\title{
EL ESTADO DE NECESIDAD COMO RECURSO PARA EL RESTABLECIMIENTO DE LA CONSTITUCIONALIDAD EN VENEZUELA
}

The state of need as a resource for the restoration of the constitutionality in venezuela

Javier Sosa*

Wilmer Carmona Urdaneta**

\section{RESUMEN}

Este ensayo presenta, para la consideración del lector, algunas razones que justifican la validez legal del ejercicio de los poderes presidenciales de manera interina, mientras avanza algunos criterios de delimitación en el ejercicio de dichos poderes. En este sentido, el estado de necesidad en Derecho Público nos permite presentar una explicación aceptable de la autorización constitucional para un estado de excepción, con el propósito de rescatar el institucionalismo político como marco de una democracia en libertad.

Palabras clave: Restablecimiento de la constitucionalidad, estado de necesidad, presidencia interina, ejercicio de potestades presidenciales.

\begin{abstract}
This essay intends to submit for the reader's consideration some reasons that justify the legal validity of the exercise of presidential powers on an interim basis, while advancing some delimitation criteria in the exercise of said powers. In this sense, the state of necessity in Public Law allows us to present an acceptable explanation of the constitutional authorization for a state of exception, with the purpose of rescuing political institutionalism as the framework of a democracy in freedom.
\end{abstract}

$1^{*}$ Abogado egresado de la Universidad del Zulia, Venezuela. Ex-juez de Primera Instancia en lo Civil y Mercantil de la jurisdicción del Estado Zulia, Venezuela. Profesor de los programas de Derecho y de Ciencia Política en la Universidad Rafael Urdaneta y Profesor de postgrado en la Universidad Rafael Belloso Chacín y en la Universidad del Zulia, Venezuela. ORCID: https://orcid. org/0000-0001-5221-7242 E-mail: javiersosapacheco@gmail.com

** Abogado egresado de la Universidad del Zulia, Venezuela. Doctor en Derecho. Profesor Titular de la Facultad de Ciencias Jurídicas y Políticas de la Universidad del Zulia, Venezuela, ex - decano de la Facultad de Ciencias Jurídicas y Políticas de la Derecho de Universidad Rafael Belloso Chacín, Venezuela. Profesor invitado de postgrado de la Universidad Sergio Arboleda, Colombia. Docente de cátedra en el programa de Derecho de la Fundación Universitaria Antonio de Arévalo (UNITECNAR). ORCID: https://orcid.org/0000-0002-8065-0147 E-mail: wcarmona@outlook.com 
Key Words: Restoration of constitutionality, state of exception, interim presidency, exercise of presidential powers.

\section{LA INSTITUCIONALIDAD CONSTITUCIONAL: UN SISTEMA AXIOLÓGICA- MENTE CONDICIONADO.}

Los holocaustos ocurridos en la primera mitad del siglo XX (exterminio judío en manos del nazismo, purgas y destierros estalinistas, instalación del marxismo en la china de Mao) provocaron, en las reservas de las conciencias morales de Occidente, un profundo cuestionamiento cultural, de tan amplia extensión que afectó los referentes conceptuales de casi todas las disciplinas. (Bozo de Carmona, 2004)

En el ámbito de la política, una profunda conciencia de la libertad, de la autoafirmación del sujeto frente al Estado, de la dignidad humana, de la inalienabilidad de ciertos valores de convivencia -resultados históricos del cristianismo y del racionalismo, junto a la conciencia política como modo liberador del ciudadano en la dimensión persona-sociedad- califican los procesos y modos de configuración de una nueva institucionalidad capaz de reaccionar ante los nuevos embates, retos y agresiones de las falsas conciencias históricas y críticas que eventualmente enarbolan banderas plétoras de muerte, humillación, hambre y sufrimiento. (Bozo de Carmona, 2005)

De este modo la conciencia ética en su dimensión política, se juridifica y, en ocasiones, se hace norma y positiviza en una estructura flexible, de densidad abierta, con vocación de inmediata aplicación, que aspira permear la totalidad del ordenamiento jurídico al crear una nueva ratio cohesionadora y articuladora de un sistema axiológica y preceptivamente comprometido con la dignidad humana.

Este nuevo emprendimiento se alza sobre viejas conquistas, las rejuvenece y actualiza, de forma que los derechos fundamentales han dejado de ser una carta de aspiraciones, un catálogo enunciativo de buenos deseos, para transformarse en antecedentes normativos eficaces de cualquier disposición jurídica general y abstracta o individual y concreta.

En este modelo constitucional la positivización, como técnica de producción jurídica, no consume ni agota el sentido de la iusfundamentalidad, no decae ella misma como referencia imputacional. Por el contrario, constituye un mecanismo de plasticidad que crea, a través del momento sígnico (lenguaje directivo escrito e intencionalmente sancionado: Derecho positivo), un momentum de referencia jurídica que traduce la adopción de ciertos presupuestos axiológicos culturalmente compartidos; así, los derechos fundamentales no solo se traducen en normas, sino también en principios orientadores que optimizan los procedimientos de comprensión y aplicación jurídicas. 
Una tal concepción comporta una renuncia expresa al carácter adiáforo o neutral de la experiencia del operador normativo, quien de esta guisa se ha transformado en militante, predicador y operador axiológicamente comprometido con cierto orden de valores, un credo constitucionalmente sancionado. Este y no otro es el sentido material de la constitucionalización de los derechos fundamentales, Hesse (2001: 92) lo expresa del siguiente modo:

"Lo decisivo de esta concepción ampliada de los derechos fundamentales fue el rechazo a su interpretación formal [...] y el giro hacia una noción material que comprende la dimensión jurídico-objetiva inserta en ellos y los concibe como principios supremos del ordenamiento jurídico al abrigo de cualquier relativización".

No obstante, las experiencias históricas han demostrado que la sanción constitucional no es suficiente para que un orden institucional despliegue su actividad acorde con el nuevo paradigma iusfundamental. Las cenizas de Birkenau, los Gulag de las frías estepas rusas, los cadáveres yacentes en los surcos de la revolución agraria maoísta, o las versiones más actualizadas del refinamiento de la tortura psicológica, son vívidos ejemplos de los derechos fundamentales convertidos en cartas de buenas intenciones o elegantes declaraciones para ser exhibidas al socaire de las tiranías.

Al nuevo paradigma jurídico corresponde un modelo cultural del espacio político: la democracia como despliegue libertario de la personalidad; únicamente una institucionalidad política que opere desde y para la democracia, que tenga como propósito y último fin materializar y hacer efectivo el modelo iusfundamental, es constitucionalmente viable. Esto, indudablemente, transforma la simetría de las relaciones en los espacios de Derecho Público y transforma los paradigmas de las relaciones político-institucionales que venían manteniendo como referencia la omnipotencia el Estado y sus instituciones. "En suma, cabe definir el principio de una democracia en libertad en este primer sentido de un orden de libertad como el orden de mayor libertad individual posible en igualdad de derechos, compatible con la necesaria seguridad jurídica de todos". (Benda, Maihofer, Vogel, Hesse y Heyde (2001: 292).

En este nuevo orden de cosas la interpretación eficiente del texto constitucional se produce a partir de la dimensión estimativa de la iusfundamentalidad y del hecho político. La institucionalidad, entonces, se transforma en instancia que asegura y arbitra la materialización de una cultura de convivencia en libertad, de forma tal que los derechos humanos y las formas políticas que los aseguran se conviertan en realidades culturalmente ostensibles.

He aquí la médula paradigmática del neoconstitucionalismo; los textos constitucionales adquieren la coherencia y sistemática que una visión meramente positivista les habría negado. Los principios políticos y los derechos fundamentales tienen la calidad de normas positivizadas y dejaron de ser 
introitos de entusiasmo político constituyente para convertirse en gründ norm o auténticas normas que presiden, rigen, orientan e informan cualquier esfuerzo de comprensión jurídica y mucho más en los procesos de intelección constitucional, de manera tal que el esfuerzo hermenéutico, en sede constitucional, que no integre estos valores, principios o derechos es ab initio inconstitucional.

Más allá de otras consideraciones que ocuparían una mayor reflexión (diversidad ontológica, metodológica o epistemológica entre reglas y principios), la institucionalidad jurídica sin la referencia estimativo-preceptiva, es ejercicio de la violencia, la implantación de la tiranía, campo en el que la irracionalidad del cratos domina al ser humano, lo degenera, lo convierte en sujeto de un conglomerado social (comunismo, corporativismo, socialismo), degradándole a cosa y por tanto subiectus, administrado, justiciable, arrebatándole su dignidad.

La dimensión omnicomprensiva de la significación como resultado de la hermenéutica constitucional es expuesta por Schneider (1991: 148):

"[...] Aparece justificada la suposición de que cada derecho fundamental muestra, a la luz del estado de derecho una significación distinta [...] En principio no obstante hay que partir de la posibilidad de generalización de todas las funciones de los derechos fundamentales. Cada derecho fundamental permite reconocer, si se analiza con precisión, tanto una significación en el estado de derecho como una significación democrática y, finalmente, una significación en el Estado Social de Derecho; por consiguiente, presenta una eficacia simultánea como elemento de defensa y elemento del ordenamiento jurídico, como derecho de participación y garantía procesal, como derecho de prestación y directriz para el legislador. Al análisis metódico de este contexto funcional de los efectos de los derechos fundamentales y de las estructuras constitucionales se podrá agradecer precisamente en casos difíciles alguna ayuda interpretativa".

Por tales razones la simetría de las relaciones de poder han cambiado y al efecto es útil señalar que:

1.- Al hombre ya no se le concibe súbdito, pues ya no será más subiectus, no está domeñado por la fuerza del Estado; por el contrario es el extremo más importante de una relación de poder (ejercicio racional y razonable de la fuerza como instancia estimativo-normativa de validez jurídica).

2.- Tampoco será considerado en adelante como administrado, pues no se le concibe como ad minister, esto es bajo la guía, orientación o gestión ajena. Es ciudadano y en tal condición está llamado a desplegar su vitalidad entre los miembros de una comunidad políticamente organizada. 3.- Pero ni siquiera se le puede concebir como justiciable en el sentido tradicional de la expresión, ya no es un súbdito pasible de administrarle justicia (así se sigue del sufijo ble usado al término del sustantivo justicia); ahora lo es en la medida en que no solo exige justicia, sino que tiene derecho a cierta calidad en la prestación del servicio, a una justicia capaz de llegar a ser efectiva (artículo 26 de la Constitución Nacional de la República Bolivariana de Venezuela, en adelante CNRBV). 
En definitiva, en el nuevo modelo constitucional parecen coincidir legalidad y legitimidad; la disociación conceptual ocurrida en Roma, aspira retornar a sus derroteros griegos y en adelante solo puede ser legal lo que también es legítimo. Este y no otro pareciera ser el carácter de la llamada vinculación material de las constituciones contemporáneas (artículo 7 CNRBV), que del lado activo representa un elemento estimativo de contenido cultural cada vez más exigente (progresividad de la iusfundamentalidad) y, en su manifestación pasiva, el límite inferior de la tolerancia de injusticia.

Elocuente en tal sentido es el autor Gustav Radbruch (2007: 79):

"A diferencia de la anterior tradición constitucional alemana del siglo XIX y comienzos del siglo XX - esta referencia en el resto de la comunidad de países occidentales se extiende hasta finales del siglo XX y en Latinoamérica, nos encontramos en pleno proceso de asimilación del nuevo paradigma - los derechos fundamentales tienen validez no por las leyes mismas, sino, por el contrario, las leyes tienen fuerza por los derechos fundamentales".

En el caso venezolano, la Constitución sancionada en 1999 no es ajena al paradigma expuesto. Al Título III que lleva por epígrafe: "De los derechos humanos y garantías y de los deberes", le preceden sancionados en el Título I, la positivización de los principios fundamentales, que a modo de conformación del espacio político, prevé las directrices estimativas para el efectivo despliegue de la iusfundamentalidad. En ese sentido los espacios políticos institucionales constitucionalizados han de ser:

1.- Democráticos: en el artículo 2 expresamente se adopta la forma del Estado democrático y, más adelante en la misma disposición, se reconoce a la democracia como valor político de convivencia.

En el marco político así delimitado, los valores generales en los que se inspiran los derechos humanos, preceptuados ex articulo 3 ibídem se refieren al: “...ejercicio democrático de la voluntad popular...", cuya titularidad y manera de ejercicio se estatuye en el artículo 5 ejusdem, para asegurar una forma de gobierno igualmente democrática, esto último según el artículo 6 de la Magna Carta.

2.- Espacios para el despliegue de libertad: Esta como valor moral fundamental (art. $1 \mathrm{CNRBV}$ ), que junto a la democracia preside la acción y comprensión del ordenamiento jurídico (art. 2 CNRBV).

Es en este espacio políticamente definido donde se materializan los contenidos del Título III ya señalado: la iusfundamentalidad en pleno, de los artículos 19 al 135 de la Magna Carta. 
La manera como se disciplinan los derechos de participación política y sus mecanismos en el texto fundamental, deja a las claras la profunda interdependencia de los derechos humanos y la democracia como espacio político (Capítulo IV del Título III de la CNRBV). Pero también existe una norma de cierre que termina por dar coherencia al sistema, al crear un deber de preservación de la democracia en libertad con eficacia iusfundamental, en el artículo 132, que impone la participación ciudadana: “...promoviendo y defendiendo los derechos humanos como fundamento de la convivencia democrática".

Para concluir esta breve exposición se podría parafrasear a Ferreyra (2013), en su obra Fundamentos Constitucionales, al afirmar que se impone una nueva forma de leer el texto constitucional; o sea que existe una nueva codificación, nuevos contenidos semánticos y la definitiva inclusión del hecho político en la comprensión constitucional desde una nueva pragmática del poder, esto es, el Derecho dúctil que señala Zagrebelsky (2011).

\section{VENEZUELA UN ESTADO EN DISOLUCIÓN}

Al instaurarse en Venezuela un régimen de izquierda, se crea un proceso de desconstrucción y desarticulación de la institucionalidad político-jurídica, la promesa de un nuevo país que aspiró crearse con el proceso constituyente de 1999, prontamente comenzó a diluirse de manera irreversible, acorde a un sistema ideológicamente comprometido que percibe el Derecho como técnica hegemónica de dominación y manipulación de los espacios políticos concebidos como escenarios de lucha, violencia y sumisión irrestricta.

La implementación práctica de la llamada revolución bolivariana o socialismo del siglo XXI, ha llevado al Estado venezolano a una progresiva disolución que amenaza con desaparecerlo y con él, los espacios sobre los cuales se desenvuelve la venezolanidad, poniendo en peligro su sobrevivencia. (Bozo de Carmona, 2008)

Expondremos, a continuación, cómo la situación actual de Venezuela es más la de un Estado en proceso de desintegración que cualquier otra figura; sus elementos constitutivos están en pleno deterioro; lo poco que queda está en grave descomposición y la acción gubernativa muestra a diario su fracaso.

En primer lugar, en la última década la población venezolana ha venido siendo afectada de manera silente y progresiva por diferentes factores relacionados con la salud y la propia existencia. En tal sentido, resultan alarmantes por su procedencia las cifras que aportan organizaciones internacionales y organismos no gubernamentales en cuanto a los índices de desnutrición, los decesos por 
deficiencias en el servicio de salud pública y privada, la falta de acceso real a medicamentos e insumos quirúrgicos y terapéuticos mínimos.

Las condiciones de salubridad pública, la reaparición de epidemias que habían sido erradicadas (sarampión, paludismo, dengue en sus dos variedades, entre otros) a mediados del siglo XX, son otras de las causas que han llevado a un descenso poblacional alarmante. Si a lo enunciado se suma la violencia social, las muertes en manos del hampa o de grupos subversivos y paramilitares organizados en Venezuela, es posible sugerir una sensible incidencia del 17\% en la disminución de la población venezolana, cifra con un progreso exponencial en tanto subsista esta alarmante situación.

La salud en general está profundamente deteriorada, la prestación del servicio de asistencia sanitaria pública y privada es más que deficiente. En lo que concierne al sistema público de salud, integrado por los hospitales regionales, universitarios y los inscritos en el Instituto Venezolano de los Seguros Sociales, junto a la red de dispensarios de atención menor, conocidos como Centros de Diagnóstico Integral (CDI), adolecen, en el mejor de los casos, del material terapéutico, clínico o quirúrgico; en la mayoría de los casos las deficiencias alcanzan al material de atención mínimo (gasas, alcohol, algodón, inyectadoras); a ello es necesario sumar el gran éxodo de los profesionales de la medicina al exterior, lo cual priva de especialistas a la salud venezolana.

El mismo efecto, pero de manera más ostensible, lo ha producido la emigración venezolana; cifras conservadoras refieren el equivalente a un diez por ciento (10\%) de la población. (León Vargas, 2018). Según la ACNUR y OIM (2019), para el día 05 de diciembre de 2019 la cifra de refugiados y migrantes en ese país era de 4.769.498. Esta cifra representa la suma de migrantes, refugiados y solicitantes de asilo venezolanos reportados por los gobiernos anfitriones; no necesariamente implica identificación individual, ni registro de cada individuo, e incluye un grado de estimación, según la metodología de procesamiento de datos estadísticos utilizada por cada gobierno. Como muchas de las fuentes de los gobiernos no toman en cuenta a los venezolanos que no tengan un status migratorio regular, es probable que el número total sea más alto.

Los servicios públicos básicos para asegurar la vida de la población se han deteriorado al punto de desaparecer parcial o totalmente. Al momento de la redacción del presente ensayo, Venezuela tiene un muy deficiente servicio eléctrico, que en numerosas ocasiones ha privado de la prestación del mismo a todo el territorio nacional y, actualmente, ha conducido a un sistema indiscriminado de racionamiento, interrumpiendo toda posibilidad de superación de la profunda crisis económica y de mantener la cordura en la cotidianidad. 
El servicio de agua potable para las principales y más populosas ciudades del país: Caracas, Maracaibo; Valencia, Barquisimeto, Maturín, Ciudad Bolívar y San Cristóbal, se ha hecho irresoluble y la paralización de la planta de producción de cloro soda en la industria petroquímica nacional hace imposible su tratamiento de acuerdo a estándares internacionales.

El transporte público es casi inexistente, la escasez y altos costos de los repuestos para vehículos y de la mano de obra, aunado al desmesurado e irracional control del Estado sobre precios y tarifas públicas como contraprestación del servicio, imposibilitan mantener una plataforma mínima de vehículos que aseguren la movilidad interna.

En cuanto a la educación, a las universidades públicas -antes principal instrumento de ascenso social- se les niega el presupuesto mínimo para su normal funcionamiento; la extorsión salarial es un socorrido medio de gobernabilidad. Los insumos para los proyectos de investigación no son oportunamente entregados o simplemente no existen.

En cuanto a la producción agropecuaria, el rebaño nacional ha decrecido en aproximadamente un treinta y cinco por ciento $(35 \%)$ y con ello una drástica disminución del consumo de proteína animal en la población. La explotación agrícola ha disminuido sensiblemente, de ser un país exportador de sorgo y arroz, en la actualidad Venezuela tiene que recurrir a las importaciones; la zafra de café ya no abastece el mercado interno, con una deficiencia de aproximadamente un $40 \%$; las semillas necesarias para la siembra no están disponibles y las que se ofrecen carecen de las fortalezas ganadas con el mejoramiento genético obtenido en años de cultivo, por ejemplo, la papa. En resumen, la publicitada seguridad agroalimentaria de la nación es solo el epitafio de otra tumba más.

Con respecto al segundo elemento fundamental del Estado, es decir, la soberanía, no solo se ha reducido la vitalidad, también han venido desapareciendo los espacios de libertad concebidos como el hábitat jurídico político institucionalizado para el desarrollo de la ciudadanía; la institucionalidad como estructura que soporta el gobierno se difumina.

La seguridad de los ciudadanos está erosionada por la enorme corrupción al interior de los cuerpos de seguridad y el control social es dejado en manos de fuerzas paramilitares; la vida, la integridad personal, la salud psicológica y el respeto de la propiedad privada, son bienes que adolecen de eficiente tutela jurídica.

Como se ha podido apreciar, los niveles de gobierno, estimados según la eficiencia de los cometidos básicos del Estado, no existen o son profundamente deficientes, por lo que se puede afirmar que el segundo elemento de la existencia del Estado está realmente comprometido. 
En cuanto al tercer elemento estructural de la estatalidad, o sea, el territorio, no es mejor la apreciación; amplias zonas de la geografía nacional están dominadas por el hampa común; otras son aliviaderos o cotas de fuerzas insurgentes extranjeras; los recursos naturales, como la faja petrolífera del Orinoco y el arco minero de la Guayana, están enajenados a Estados extranjeros en una suerte de neocolonización.

La argumentación precedente con respecto a la realidad venezolana en la época actual, es solo una enumeración ad exemplum, más que suficiente para concluir que, la República Bolivariana de Venezuela, es un Estado con un gobierno que no cumple la función de satisfacer las necesidades más elementales de la población del país.

Los elementos constitutivos del Estado, según la teoría clásica, se están difuminando bajo la inerte indiferencia del gobierno; la población es sistemáticamente agredida, horadando progresivamente esos lazos culturales que la cohesionan e identifican, sus miembros desaparecen al morir o deciden emigrar, cada vez son menos los venezolanos que se asientan en el territorio de la antigua Capitanía General de Venezuela.

La gobernabilidad, esa incidencia efectiva en la materialización de las prestaciones públicas como modo de satisfacción de los intereses de la población, no existe o es de tal deficiencia que se constituye en fuente de ansiedad y desesperanza.

Por último, la retirada en la defensa de los espacios geográficos patrios o la deficiencia de control institucional, impiden que la población se asiente o pueda desplegarse libremente en el territorio nacional.

Así las cosas, un modelo de Estado cuya institucionalidad se encuentra axiológicamente condicionada, tiene severamente comprometida su existencia, no puede garantizar los espacios de despliegue político o privado de la población. En una democracia con libertad, la imposibilidad del desenvolvimiento libre de la iusfundamentalidad, condicionante de la dignidad humana, se ha perdido en las largas colas de los ancianos, en las muertes por falta de medicamentos o insumos médicos, en el llanto de un niño que se apaga al no sentir más hambre en su cuerpo colapsado.

Ante este estado de cosas, el texto fundamental sancionado en 1999 contempla un último mecanismo institucional, existente en la coordinada interpretación de los artículos 333 y 350, lo que puede ser considerado como una clara manifestación, en Derecho constitucional, de la figura del estado de necesidad. 


\section{EL ESTADO DE NECESIDAD EN DERECHO PÚBLICO}

1.- Algunos antecedentes, nuevo nombre a una antigua institución.

"Nihil novit sub sole", no hay nada nuevo bajo el sol, y la existencia de mecanismos jurídicos extraordinarios como medios para superar las crisis político- institucionales o de preservar el marco jurídico institucionalizado, tampoco lo es.

Desde los líderes tribales en las sociedades primitivas hasta las actuales cláusulas constitucionales de habilitación inspiradas en el estado de necesidad, son maneras en que la interacción política de las sociedades concibe formas para mantener la institucionalidad cuando esta es amenazada (medidas de alta policía, estados de excepción) o para restablecerla cuando ha resultado temporalmente fracturada.

La longevidad de la figura jurídica del estado de necesidad es posible referirla, con registros históricos claros, al Derecho público de la antigua Roma republicana, en la que se preveía la elección de un líder carismático, particularmente dotado de habilidades militares y políticas (posible origen de la monarquía previa a la República), en quien temporalmente (seis meses), recaía la conducción de la res publicae, o sea, la institución de la Dictadura. (Carmona, 1998)

En efecto, Tito Livio (27-25 A.C/1997) en su famosa Historia de Roma, refiere que en la Roma republicana era usual el nombramiento de un funcionario llamado dictador, para regir los destinos del Estado cuando la gravedad de las circunstancias así lo exigían.

También Costa (1930: 113) se refiere a la dictadura durante la República romana de la siguiente manera:

“28. Las disciplinas y normas...que rigen durante la República al consulado y a las otras magistraturas ordinarias y permanentes sufren suspensiones por anormales y supremas necesidades de peligros externos o internos, que amenacen al Estado; proveyéndose según los términos fijados en la misma constitución, en previsión de estos peligros, mediante el recurso a una única magistratura, que ya fue conocida por algunos de los pueblos itálicos que precedieron a los romanos; la magistratura del praetor maximus o magister populi o como se le llamó más corrientemente dictator".

La extensión de las facultades atribuidas al Dictador como magister extraordinem, son enunciadas por Theodor Mommsen (2015: 276): 
"Tenía la dictadura una particularidad que se explica, no obstante, por el mismo carácter extraordinario que revestía el cargo. Esta facultad consistía en corresponder por derecho político al dictador la plenitud del poder, y, sin embargo, limitarse de hecho a ejercer facultades determinadas. Pues, mientras por derecho podía el dictador desempeñar cualesquiera y todos los asuntos propios del cargo consular...en cada caso concreto se le nombraba para que desempeñara un negocio determinado".

La particularidad de la institución consistía en investir un magistrado extraordinario como consecuencia de una emergencia político-jurídica, bien por conmoción interna (revuelta de los hermanos Graco), bien por necesidades bélicas (invasión de Aníbal en las guerras púnicas) que comprometieran la estabilidad de la civitas (Tito Livio usa el adjetivo "trepidus"). Al magistrado, así nombrado, se le otorgaba una extraordinaria potestas (especialmente las limitaciones introducidas a la colegialidad del consulado) que le facultaba para la adopción y ejecución de decisiones políticas sobre la marcha de los asuntos públicos, mientras perdurara la situación de emergencia y con el fin de superar la situación de conmoción. Una vez que la situación de conmoción cesaba, de inmediato se restituía la normalidad institucional.

Para el ejercicio de esta magistratura existían límites objetivos: se instituía al dictador para superar una situación que se le defiere en el cargo (generalmente una campaña militar) y por tiempo determinado (seis meses, la duración de una campaña militar de verano. Uno y otro límite servían de referencia político-jurídica al encargo. Junto a los límites objetivos se exigían ciertas condiciones personales que develan, en parte, la naturaleza de las decisiones que debía asumir el dictador. Quien era nombrado dictador, generalmente había ejercido la dignidad consular y por tanto contaba con la experiencia política que le proporcionaba el haber transitado el llamado "cursus honorum", y encontrarse, por tanto, en la cumbre de las magistraturas (solo le faltaba en ocasiones la censitaria, que como custodes mores, tenía más incidencia ética que político-jurídica), lo que presuntamente, al menos, le dotaba de las condiciones de experiencia necesarias para tomar y ejecutar las decisiones más atinadas, para enfrentar y enderezar la situación y mantener la actuación del dictador sino intra legem, al menos secundum mores.

Al efecto es elocuente que durante las guerras púnicas, cuando Aníbal fue el comandante de las fuerzas cartaginesas, la dignidad de la dictadura recayó en Roma en Quintus Flavius Maximus, quien llegó a ocupar la dignidad consular cinco veces, y no en alguno de los Escipiones, pese a que Publio Cornelio Escipión (Africanus), dirigía exitosamente la campaña en África.

En Roma, (inclusive antes del Derecho romano helenizado), el ejercicio de una potestas de carácter público, por tanto revestida de imperium et autorictas, excluía la aspiración a la satisfacción de un daño indemnizable, puesto que el magister (pretor) había sido autorizado a penetrar en la órbita del 
cives, siendo claro que en situaciones particulares, de Derecho Público o Privado, caracterizadas por su poca frecuencia y sugeridas por la necesidad de superar una situación de una magnitud capaz de comprometer o hacer desaparecer ciertos bienes jurídicos, se permitía la violación de las previsiones honorarias, como una situación excepcional.

Siguiendo el rastro histórico del estado de necesidad observamos que las previsiones del Derecho romano quedan suspendidas ante la penetración bárbara del territorio del antiguo Imperio Romano de Occidente. Las tribus de origen germánico, franco y visigodo implementaron, durante la conquista, sus principios jurídicos, en especial el derecho de conquista y de guerra, el cual sustituirán con una legislación progresivamente influida por el Derecho romano, una vez asentados en sus nuevos territorios, (Vgr. Codex Alaricum o Código de Tolosa) que, a modo de costumbre, había permanecido en Europa.

En la Alta Edad Media, que coincide con el llamado Renacimiento o florecimiento medieval en el pensamiento de Occidente, se inicia la reelaboración del Derecho romano, ahora "secundum modus escolasticorum " al adoptarse como modelo metodológico la lógica aristotélica y el proceso demostrativo deductivo de la escolástica, por la escuela de los glosadores. En esta época se formula la categoría jurídica de los status (estados) de manera definitiva y es a los legistas financiados por el Emperador del Sacro Imperio Romano Germánico, a quienes corresponde el mérito de convertir el estado o status en "la posición que ocupa un hombre en la sociedad política", como afirma Helmut Coing (1996: 221). Más adelante se retomará esta referencia para perfilar la noción de estado de necesidad.

Sin embargo, en la esfera práctica, pese a iniciarse el desarrollo de la reconstrucción teórica del Derecho, el casuismo se mantiene y así, en las fuentes de canonistas y legistas al servicio de los principados y burgos, se alude por ejemplo en los casos de expropiación a la "urgens necesitas" (Coing, 1996: 212). Como puede observarse se mantiene la referencia a la necesitas como expediente para la habilitación de una actuación jurídica extraordinaria, fuera de lo común, anormal.

Es también en el medioevo, en la actividad de abstracción y generalización inductiva emprendida por los canonistas, cuando se acuña la expresión: necesitas non habent legem (la necesidad está sustraída a la legalidad) y desde entonces ha servido de referencia para describir el funcionamiento del estado de necesidad como ruptura de la legalidad (es necesario ser cautos al momento de adoptar la sentencia a manera de principio orientador, pues no puede entenderse que quien actúa en estado de necesidad lo hace de legibus solutus, sin ningún tipo de referencia normativa, sólo que queda temporalmente sustraído de la juridicidad ordinaria).

En adelante la institución seguirá su progresiva formación, pero siempre será percibida como un discontinuo de la juridicidad en tiempos de normalidad, un quebrantamiento temporal de la legalidad en holocausto a la legalidad, a la preservación ulterior de la misma. 
Como ha podido observarse, la institución del estado de necesidad en su dimensión jurídica pública no desapareció con el ocaso republicano de Roma; al contrario, se restableció en la Alta Edad Media y fue objeto de análisis particulares en el renacimiento romántico de la filosofía política de la Ilustración francesa. Incluso, en la historia venezolana la dictadura recayó en el Libertador, en un último intento desesperado de salvar la Gran Colombia.

Es importante destacar que la historia jurídico-política muestra instituciones creadas con el propósito de enfrentar situaciones que atentan contra la institucionalidad del Estado y que no tienen más justificación que la reacción a la necesidad de mantener, restablecer o recuperar la institucionalidad constitucional, impuesta como necesitas iure, y a eso se le denomina estado de necesidad.

\section{2.- Acercamiento conceptual.}

Los hechos que preceden a la adopción de la figura se expresan de manera elocuente en la expresión latina necesitas, cuya etimología se hace derivar de dos raíces latinas: del adjetivo necesse que coincide con el significado esencial de necesitas: inevitable, inexorable, forzoso, necesario, y de la partícula atis, que es la forma gramatical que como sufijo adopta en latín la palabra átrox y que en este caso denota que la fatalidad del necesse es cruel, siniestra, grave, y así necesitas desde el punto de vista semántico traduce: fatalidad, necesidad, lo inevitable, el destino. La locución parece expresar bastante bien la reacción del ciudadano romano o medieval ante una situación que se calificaba de necesitas: lo imprevisto, sorpresivo, lo inesperado que provocaría un daño. Desde la perspectiva de la institucionalidad política, en particular en la Roma republicana (después de la mítica caída de la monarquía; la liberación del Derecho de los oráculos sacerdotales y la conmoción de los Graco), la perturbación a la conciencia de estabilidad se percibía como la mayor de las desgracias y desventuras, una auténtica anormalidad para una cultura con un alto sentido político. Es en este detalle en el que la necesitas interviene para provocar y facilitar las acciones que permitían controlar la situación, por ello se habilitan mecanismos de urgencia que temporalmente suspendían, quebrantaban o fracturaban la juridicidad ordinaria prevista para tiempos de estabilidad política-gubernamental y se adoptaban las medidas extraordinarias de matiz jurídico diverso, con un alto contenido político.

El otro miembro de la expresión: estado, se agrega probablemente en las postrimerías de la Baja Edad Media, cuando ya la escuela de los glosadores y legistas había construido de manera más o menos definitiva la teoría y el sistema de los estados, que quedaron concebidos como referentes subjetivos de concentración imputacional, es decir, con ellos se trata de aglutinar todas las relaciones y situaciones jurídicas que correspondan a un mismo sujeto como referente del material jurídico aplicable (en la actualidad se corresponde bastante bien con la teoría de la situación jurídica). 
Corolario de lo expuesto sería entender por estado de necesidad en general, la habilitación temporal de juridicidad extraordinaria, que autoriza u obliga a un sujeto a adoptar las conductas requeridas para restablecer los referentes ordinarios de imputación jurídica.

\section{3.- Soporte normativo.}

La norma constitucional contenida en los artículos 333 y 350 de la Constitución Nacional de la República Bolivariana de Venezuela, sanciona el estado de necesidad constitucional para la restitución de la institucionalidad. Estos preceptos habilitan la actuación política y jurídica que se propone rescatar la institucionalidad como democracia en libertad, para restituir los espacios de una efectiva iusfundamentalidad, restituyendo el Estado como instancia de desarrollo vital.

Las disposiciones constitucionales citadas prevén:

Artículo 333: Esta Constitución no perderá vigencia si dejare de observarse por acto de fuerza o porque fuere derogada por cualquier otro medio distinto al previsto en ella.

En tal eventualidad, todo ciudadano investido o ciudadana investida o no de autoridad, tendrá el deber de colaborar con el restablecimiento de su efectiva vigencia.

Artículo 350: El pueblo de Venezuela, fiel a su tradición republicana, a su lucha por la independencia, la paz y la libertad, desconocerá cualquier régimen, legislación o autoridad que contraríe los valores, principios o garantías democráticos o menoscabe los derechos humanos.

En el primer aparte del artículo 333, se insiste en la supremacía de la Constitución, se resalta la aspiración a la perpetuidad del texto y del sistema constitucional desarrollado acorde a él, como valores dignos de protección. Inmediatamente, el segundo aparte habilita a cualquier ciudadano de la República a emprender las acciones que fueren necesarias para restituir la eficacia de la Constitución.

Por su parte, el artículo 350 insiste en la supremacía constitucional, lo hace desde la perspectiva del soporte axiológico en el que se edifica la institucionalidad del modelo democrático y la iusfundamentalidad sobre la cual se sustenta. La disposición comentada ha sufrido con el transcurrir del tiempo múltiples interpretaciones, todas ellas ideológicamente interesadas. Como un supuesto derecho subjetivo público a la revolución, lo concibieron las izquierdas de Venezuela, en un artículo similar que se encontraba en la Constitución de 1961. De derecho político a la resistencia ha sido calificado y constantemente invocado por las tendencias que se auto califican de opositoras al régimen. Por último el Tribunal Supremo de Justicia le ha llamado cláusula de estabilidad democrática, tratando con ello, de manera aviesa, de sustraerle cualquier contenido de intervención activa en la restauración política. 
En este contexto, creemos que el artículo 132 del Texto Fundamental pudiera aportar algunos elementos que permitan adelantar argumentos jurídicos más provechosos en la intelección de la institución contenida en el artículo 350. Prevé el artículo 132:

"Toda persona tiene el deber de cumplir sus responsabilidades sociales y participar solidariamente en la vida política, civil y comunitaria del país, promoviendo y defendiendo los derechos humanos como fundamento de la convivencia democrática y de la paz social".

Este texto ya se ha mencionado y se le calificó como estructura de cierre en nuestro sistema iusfundamental. En él se contiene un mandato de actividad, un facere dirigido a toda persona que habite en el territorio venezolano, en cuanto se le exige la adopción de una conducta proactiva para la promoción de espacios políticos colmados de libertad y, de ser necesario, en la defensa de los mismos. Este último supuesto viene delimitado por la descripción semántica que la Real Academia de la Lengua hace del verbo defender, pues junto a amparar y conservar, enuncia liberar, última acepción que sin duda alude la adopción de un comportamiento positivo, capaz en sí mismo de promover una modificación en el entorno del sujeto actuante, lo que por demás se compadece con el contenido de la norma cuando advierte: “...cumplir sus responsabilidades y participar solidariamente en la vida política, civil y comunitaria del país..." Es en este sentido que debe entenderse el desconocimiento que menciona el artículo 350, por eso no es solo una resistencia, un pati (soportar) la acción inconstitucional, sino indudablemente una resistencia activa que requiere la adopción de iniciativas que materialicen la protección de la institucionalidad constitucional.

Similar es la intelección que debe asignársele al vocablo colaborar que encabeza el dictum de la parte in fine del segundo aparte del artículo 333 de la Magna Carta, en clara alusión a la participación en la vida política, que ya estableció el artículo 132 ejusdem.

En vista de los argumentos vertidos, es falso que sancione un supuesto derecho subjetivo político a la revolución. No está habilitada la rebelión contra los valores, principios y derechos fundamentales constitucionalmente establecidos; por el contrario se impone la defensa de una institucionalidad y gobernabilidad acorde a ellos, y precisamente es la distorsión sensible entre gobierno e institucionalidad de la democracia en libertad, lo que provoca la adopción de los mecanismos de habilitación de la resistencia activa ciudadana.

Ahora bien, ¿Es esta resistencia activa un derecho, una obligación, un deber? Creemos que ninguna de las tres instancias categoriales proporciona la respuesta, en la que hay que introducir una distinción sugerida por el material normativo y es cuando la actividad la emprende un ciudadano o cuando la asume un funcionario público. 
Como refiere Jellinek (1954) no es un derecho subjetivo público, puesto que según la más consolidada corriente, siendo el correlato del derecho un deber de prestación por parte del Estado, esta es $a b$ initio inexistente, o cuando menos temporalmente imposible de ejecutar por el Estado, por estar fracturada la institucionalidad constitucional encargada de satisfacerlo. Concebirlo como derecho comportaría una verdadera aporía lógica: acudir a instancias de una institucionalidad que perdió su referente constitucional, para exigir el retorno a la constitucionalidad. Otro elemento que impide calificar la institución de derecho subjetivo público, es que el mandato está dirigido a toda persona o ciudadano individualmente considerado, sin importar que el ejercicio de la conducta por su parte sea realizado uti cives.

Tampoco constituye una obligación, pues carece de la alteridad, la heteronomía de la exigencia en el actuar, que se materializa a través de la posibilidad de la demanda ajena; no es posible identificar quién se encuentra investido para la exigibilidad de la reacción ante el incumplimiento o riesgo de inobservancia. La estructura de la relación de obligación es necesariamente bicondicional; solo cuando existen dos conductas dotadas de sus particulares roles (acreencia y débito) hay obligación, a ello se refiere el adstringimur o constreñimiento de la definición ulpiniana de la obligación; no habiendo quien exija la conducta, no hay obligación.

En definitiva tampoco ingresa en la categoría de deber como figura omnicomprensiva de la pasividad jurídica, puesto que amén de la imposibilidad de exigir la conducta, lo cual según se ha dicho lo excluye de la obligación, tampoco existe sanción alguna asociada a la falta del deber de colaboración o asistencia para la restitución de la institucionalidad, como sería por ejemplo la pérdida de los derechos políticos o el acceso al servicio público.

Al parecer el concepto de potestad es el que mejor se corresponde y describe la institución, pues parecería estarse en presencia de una habilitación para el accionar, impuesta en razón de la función político-institucionalmente diseñada, la recuperación o rescate de la institucionalidad constitucional.

El análisis aislado de cada una de las disposiciones constitucionales mencionadas, traduce por sí mismo un particular significado, pero solo la comprensión coordinada o concatenada, revela una dimensión mucho mayor, en la que el ciudadano, la persona, verdadero y último receptor de la actividad pública y beneficiaria de los espacios democráticos en libertad, resulta investida de una auténtica función pública; a saber, la de asumir las conductas necesarias para hacer efectivos y materializables los espacios de convivencia y desarrollo político y aquí, precisamente, se encuentra el concepto funcional exigido por la definición de potestad. Que sea una función que esté claramente establecida en el texto normativo pero, al modo de la dictadura en la Roma republicana, se convoca solo 
cuando la excepcionalidad de la situación hace peligrar o amenaza con provocar la desaparición de la institucionalidad secundum constitutionem.

Hasta ahora del argumento adelantado, el estado de necesidad constitucional para el restablecimiento de la institucionalidad, aparece como una potestad genérica de reacción constitucional dirigida a cualquier habitante de la República y que, por tanto, adolece de la investidura de funcionario público; sin embargo, cuando a la potestad genérica se suma el contenido de las potestades del cargo, la habilitación para la actuación es doblemente exigida, ya no es meramente una potestad funcional que se atribuye a cualquiera, sino que a su condición de persona y ciudadano, se asocia la de funcionario público y con ello adquiere la característica de obligatoriedad y desempeño del oficio iura, y como tal, de un verdadero y propio deber de desempeño del cargo. Así se infiere de la armonía en la comprensión normativa de los artículos 333, 137, 138 y 39 del texto constitucional.

No es casual que en el contenido gramatical del segundo aparte del artículo 333 se hable inicialmente de "ciudadano revestido o no de autoridad", puesto que aun cuando aparentemente se sanciona la potestad con la misma intensidad de exigencia, lo cierto es que para el funcionario sí entraña un verdadero deber impuesto por el cargo, y aquí la naturaleza jurídica, si bien sigue siendo la de una potestad (posibilidad de actuación en Derecho público), también es un deber, en razón de la relación de empleo público que media entre el titular y el Estado, condición que prevalece pro tempore, mientras perdure su relación funcionarial.

En tal sentido, la fórmula del juramento de asunción de un destino público, establece claramente, como deber básico, la defensa y el cumplimiento de la Constitución.

Es el caso del ciudadano Juan Guaidó por su condición de Presidente de la Asamblea Nacional de la República Bolivariana de Venezuela, receptáculo de la auténtica representación de la soberanía nacional (artículo 5 CNRBV), aunado al hecho de asumir interinamente las funciones de la Presidencia de la República. Esa doble condición le exige a él y a todos los miembros del parlamento, actuar, ya no solo como ciudadanos, sino en su condición de funcionarios públicos, diputados electos, a quienes podría su omisión aparejar responsabilidad penal, administrativa, política y patrimonial; en tal sentido, para ellos constituye una verdadera y propia obligación en tanto el Estado se vislumbra como instancia heterónoma de exigibilidad de su conducta.

Así pues, la habilitación de la juridicidad extraordinaria tiene un origen constitucional, es una auténtica potestad llamada a la restauración o recuperación de la institucionalidad, por ello exige a los sujetos la adopción de conductas proactivas para la reconfiguración de los espacios democráticos y de libertad para el despliegue de la vitalidad cotidiana. La norma de la Carta Magna supone la 
existencia de condiciones extraordinarias, irregulares, alarmantes, capaces de poner en peligro la institucionalidad del Estado o del Estado mismo, de allí la premura en el actuar. Como puede observarse en la exposición precedente, aquí se ven reproducidas las notas características de la figura jurídica del estado de necesidad, con sus peculiaridades de excepcionalidad, urgencia e irrupción en la juridicidad ordinaria.

4.- Configuración de los supuestos de la potestad.

Seguidamente se desarrollará superficialmente la definición ensayada a través del análisis de sus premisas, realizando las constantes y necesarias referencias al proceso político venezolano en la actualidad, como modo de validación de la argumentación sostenida en este ensayo, según la cual nos encontraríamos en una típica situación de estado de necesidad.

No obstante ubicarse en el ámbito del Derecho político o constitucional las primeras manifestaciones del asunto, han sido los cultivadores de la ciencia del Derecho penal quienes a partir de finales del siglo XIX han impulsado su estudio y logrado su mayor sistematización. Por esta razón, en adelante se acudirá a algunos desarrollos de dicha disciplina, en cuanto sean considerados aplicables a la presente investigación, pues según la aguda observación de Reinhart Maurach y Heinz Zipf (1994: 464):

"El estado de necesidad puede ser conceptuado para todas las ramas del Derecho y respecto de todas las formas de aparición de esta figura jurídica, como un estado de peligro actual para intereses reconocidos, el que solo puede ser superado mediante la lesión de intereses reconocidos de un tercero...Esta formulación conscientemente amplia demuestra que bajo el mismo concepto 'estado de necesidad', se pueden reunir diversas formas, distintas colisiones de intereses y que el campo de tensiones del estado de necesidad, es extraordinariamente amplio" (Las cursivas son del autor).

4.1.- El estado de necesidad, una situación de juridicidad extraordinaria.

Los materiales dispuestos para que el operador jurídico proceda a la construcción de las soluciones de conflicto, se erigen en lo que es el diario acontecer dentro de una cultura con valores, intereses y bienes ordinariamente compartidos; este material condiciona y delimita el desempeño de la conducta del hombre como actor cultural y proporciona los elementos identificables que perfilan la convivencia. En este sentido las actividades de producción jurídica a cualquier nivel se inspiran y en una gran proporción aspiran proteger, realizar, promover y asegurar dichos materiales. La agresión de tales valores provoca una reacción jurídica negativa desde cualquiera de sus particulares formas; penas, multas, sanciones administrativas, nulidades, conminaciones, ejecuciones forzadas, indemnizaciones, todas tienen en común el estar institucionalizadas, ya que cada una de 
ellas requiere el previo agotamiento de la vía procedimental previa dirigida a establecer la "certeza histórica" de los supuestos de solución, mecanismo que ex se requiere la inversión de tiempo que distancia por propia necesidad la solución y la superación de la anormalidad jurídica.

Sin embargo, la juridicidad no es indiferente ante condiciones irregulares poco frecuentes o consideradas culturalmente como excepcionales, para tales casos también contempla soluciones o paliativos conducentes a superar las tensiones o fricciones con lo que considera la armonía ideal de los valores, intereses, bienes y modos de convivencia que promueve y que, por ser disfuncionales las vías institucionales previstas para tiempos de normalidad, requieren habilitar otra suerte de recursos. Estos recursos están dirigidos a restituir la expectativa del modelo jurídico, por ello se habilitan soluciones que se proponen: remover la distorsión dentro del sistema, crear una situación jurídica lo más cercana y satisfactoria posible, asegurar el restablecimiento de la "normalidad" por obra de la manera más breve y efectiva.

Por último, la reacción jurídica puede consistir en idear mecanismos para recuperar o restablecer la normalidad. En estos casos, la reacción del Derecho no puede crear modos de regulación interina de la convivencia con la excepcionalidad prevista, ni tampoco tratar de mantener inalterable la situación anómala, creando realidades jurídicas de satisfacción para el sacrificio impuesto a alguno, convirtiéndola en permanente. En el caso de que la tensión entre bienes, intereses y valores jurídicamente considerados, sea de tal magnitud que la fricción comprometa en sí misma la estabilidad jurídica y la aspiración solutiva que subyace al modelo cultural de convivencia, el Derecho se ve forzado a concebir modos de ponderación de compatibilidad o sacrificios de valores, intereses o bienes para restituir la juridicidad ordinaria que se encuentra en peligro o ha sido subvertida. Este es el supuesto del estado de necesidad.

Cuando el Derecho reacciona ante situaciones que considera extraordinarias según los supuestos de convivencia culturalmente admitidos, lo hace dentro de la juridicidad, una que se aparta de los modos comunes o previstos para situaciones cotidianas a las que dirige sus modos de solución, pero que habilita en la medida en que los módulos de evaluación de las situaciones aconsejan soluciones diferentes, las más de las veces caracterizadas por su violencia (muerte en legítima defensa), abierta contradicción con las soluciones previstas para la cotidianidad (asunción de una pérdida patrimonial) o sacrificio de los medios ordinarios de solución de conflicto (Echazón y salvamento en el Derecho marítimo; , todos ellos constituyen remedios excepcionales, pero dentro de espacios de juridicidad.

El estado de necesidad siendo un mecanismo de reacción extraordinario es, no obstante, propio de la juridicidad; la ejecución de las conductas por quien actúa en estado de necesidad son lícitas y, en 
Venezuela, el estado de necesidad constitucional para el restablecimiento de la institucionalidad, cuenta con soporte normativo, tal como quedó establecido con anterioridad.

En el caso particular de la habilitación constitucional del estado de necesidad, la legitimidad del actuar deviene de las condiciones fácticas que comprometen la institucionalidad. Para ello no se requiere, de parte del sujeto que actúa en dicha situación, la conciencia de la actuación como presupuesto de la figura; quiere decir que, a los efectos del estado de necesidad que estudiamos, la gravedad de la situación política, la disolución de la institucionalidad o la desaparición del Estado, son en sí mismas justificantes de la conducta asumida.

En sede materiae resulta improcedente la disputa que en materia penal se entabló hasta las elaboraciones Goldschmidt (1954), sobre si constituía el estado de necesidad una causa de justificación o un supuesto de exculpación, basándose la diferencia en la evaluación de la intención como presupuesto normativamente calificado de la culpa en el tipo. En el estado de necesidad constitucional para el restablecimiento de la institucionalidad, la condición de legitimidad de las conductas adoptadas resulta de la facticidad política y no de consideraciones volitivas.

El anterior argumento permite afirmar que el Presidente Interino Juan Guaidó y demás miembros de la Asamblea Nacional, no son censurables por la asunción de las conductas encaminadas a recuperar la institucionalidad. No lo son política, administrativa, civil o penalmente, puesto que con la mera constatación del proceso de disolución del Estado venezolano, queda habilitada la institución jurídica sub examine, haciendo lícita su conducta por estar comprometida en la recuperación de la institucionalidad y los valores que la soportan. Al efecto es atinada la cita de Claus Roxin (1997: 570)

“1. ¿Las autorizaciones o derechos o intromisión del Derecho Civil o del Derecho Público excluyen en todos los casos y circunstancias la antijuridicidad de una conducta típica?

'A la pregunta hay que responder afirmativamente. Sería una contradicción axiológica insoportable... que una conducta autorizada en cualquier campo del Derecho no obstante fuera castigada penalmente".

Un argumento decisivo adicional a las consideraciones realizadas es que, en el caso particular de la habilitación del Presidente y demás miembros de la Asamblea Nacional, lo han sido para el ejercicio de las potestades atribuidas a su condición de titulares de un destino público de elección popular, representando directamente al soberano. Günther Jakobs (1995: 548), en su Tratado de Derecho Penal, al abordar lo referente al ejercicio del cargo y oras causas de justificación propias de especiales ámbitos de regulación, nos aclara que: "En muchas leyes son concedidas autorizaciones para la actuación 
oficial, permitiéndose expresamente la intervención con determinados fines...o bien se prescribe un fin de la actuación que no se puede alcanzar sin su intervención”.

4.2.- El estado de necesidad constitucional para el restablecimiento de la institucionalidad democrática supone la solución de la tensión de valores y la elección en la protección de algunos de ellos.

La conmoción o turbulencia social, en consideración para la activación de un estado de juridicidad extraordinaria, exige una distorsión o alteración en la vocación de materialización de un orden de valores jurídicamente considerados dignos de protección y, en el caso del restablecimiento de la constitucionalidad y sus instituciones, del rescate de los elementos estructurales del Estado.

Alguna somera y superficial referencia al valor se precisa para la intelección de la argumentación que sigue. Intuitivamente se considera como valor a manifestaciones culturales que suplen sentido y cohesión estimativa a la actuación humana. La sensibilización o manifestación material del valor es esencialmente sígnica, es decir se expresa través de realidades que le sirven de soporte o receptáculo, verbigracia, los valores estéticos en las expresiones artísticas. Los valores tienen vocación de reproducirse en la realidad, de materializarse, para aportar sentido, utilidad, importancia y dignidad al hecho humano.

En el Derecho los diversos materiales de configuración normativa son vehículos de manifestación valorativa; en ellos, el operador e imperador normativo incluyen juicios de lo que, como parte de una interacción cultural, consideran útil, digno, importante, portador de sentido y de cohesión social; de allí que en cada estructura o pieza de material jurídico subyace un valor que la califica y dota de sentido.

Esta consideración es particularmente trascendente para el Derecho constitucional occidental, que al erigirse en la iusfundamentalidad, realiza una elección estimativa, una propuesta de libertad y una aspiración de desarrollo humano en sociedad. A estos valores nos hemos referido ya y configuran el entramado que, a modo de savia, enriquece y nutre el tronco de la institucionalidad política; son la argamasa de una acertada ingeniería institucional. Por ello, la alusión a la supremacía constitucional, a la materialidad del Derecho constitucional, a la gürnd norm, por el artículo 7 CNRBV de la Carta Fundamental hace implícito el aseguramiento de la eficacia de los valores en los que se inscribe la juridicidad constitucional.

La estructura estimativa del sistema del Derecho la refiere Amir Kauffmann (1977: 99), conforme al pensamiento de Karl Binding, de la siguiente manera: 
"2. Pero la norma no sólo es válida, En ella está incluido un juicio de valor; sin embargo, no es simplemente un juicio de valor, ya que precisamente expresa un "deber hacer", y no un "deber ser". Al momento axiológico se agrega otro teleológico: la norma obliga a algo, el objeto de juicio de valor es pensado como tarea, como meta...En la vinculación mediante el Derecho y sus formas de pensamiento, la norma, confluyen, pues lo axiológico y lo teleológico...".

Y más adelante el mismo autor (Kauffmann, 1977:101), concluye:

"La consideración de la conexión lógica entre norma y juicios de valor ha conducido a los siguientes resultados:

1. A toda norma precede un juicio de valor.

2. Este juicio de valor y la norma tienen el mismo objeto.

3. Las normas están constituidas por juicios de valor acerca de actos".

Cuando en los hechos se observa una aguda contradicción entre el orden axiológico presupuesto en los materiales de elaboración jurídica y la realidad social, se hace necesario restituir el orden trastocado. Esta es una de las condiciones que preceden la habilitación de la juridicidad extraordinaria a la que ya referimos. Esta contradicción incide negativamente en la conexión entre la realidad jurídicamente considerada y el juicio de valor que subyace a ella; por tanto, provoca un cuestionamiento sobre el estado de cosas y la necesidad de restituir la disciplina axiológica. Más aún cuando la negación de los valores subyacentes no puede restituirse a través de los mecanismos de la institucionalidad ordinaria y la perturbación compromete la estabilidad del sistema. Entonces se requiere de la acción dirigida a restablecer la instancia valiosa. No obstante una enorme dificultad se asocia a la aparente facilidad: la identificación de los valores jurídicamente considerados y la fijación de la jerarquía entre ellos según los materiales jurídicos que les soporten.

El Derecho como sistema crea un cierto orden axiológico, determinada jerarquía de valores según las situaciones que exigen su intervención, inicialmente se exige del operador normativo la realización de una actividad de comprensión que le permita develar para el caso concreto la particular estructura estimativa.

En los casos de necesidad la tensión queda expuesta y la fricción asociada a ella requiere de la intelección y elección de determinado orden de valores, así como el sacrificio, negación y cercenamiento de tutela de los otros valores que se encuentran en conflicto con ellos a los que el ordenamiento jurídico también considera dignos de protección, pero que está dispuesto a sacrificar por otros de mayor relevancia para el sistema. A esto se refiere la doctrina penal y civil como el conflicto entre bienes e intereses jurídicos. 
Que estos valores sean susceptibles de ser tutelados a través del estado de necesidad, no es ajeno al pensamiento jurídico. Hans-Heinrich Jescheck (1981: 492) advierte: "El estado de necesidad puede referirse, pues a todo bien jurídico, incluso los de la comunidad (por ejemplo suministro de comestibles, seguridad del tráfico, interés de la existencia del Estado)”.

A su vez, Günther Jakobs (1995: 498), expone:

"No se puede conceder que junto al artículo 20.4 GG, no haya lugar para el auxilio del estado de necesidad del Estado. El artículo $20.4 \mathrm{GG}$ regula el derecho de resistencia incluso contra los propios representantes del Estado (contra la alta traición desde arriba) sobre todo contra los representantes del poder ejecutivo, pero limitado a una situación de emergencia para la existencia del Estado".

En Venezuela, la asunción de las funciones de la Presidencia de la República por quien ostenta la titularidad de la Presidencia de la Asamblea Nacional, dada la inexistencia de Presidente electo, es solo un síntoma más del proceso de disolución del Estado venezolano, la pérdida de la institucionalidad y en definitiva de los valores adoptados por el constituyente de 1999 como paradigma de país. El modelo de cultura y convivencia han quedado ausentes de la vida pública, en su lugar el despropósito, la anarquía, improvisación y el vandalismo son los nuevos referentes axiológicos; en tal situación, la decadente institucionalidad a la que solo puede atribuirse un valor meramente formal, trata de sobrevivir en claro fraude a la democracia. La acción de la presidencia interina tiene que dirigirse, constitucionalmente, al rescate de la institucionalidad perdida, al auxilio de los espacios de una democracia en libertad, al aseguramiento de la efectiva vigencia de los derechos fundamentales; solo en esta referencia y propósito es que encuentra su legalidad y legitimidad la habilitación del estado de necesidad y por ello, en adelante su actuar debe tener como dirección o propósito el rescate de la institucionalidad y, solo una vez recuperada, el retorno a la constitucionalidad ordinaria.

4.3.- El estado de necesidad constitucional para la restitución de la institucionalidad habilita una efectiva intervención para el cese de la desinstitucionalización.

La juridicidad extraordinaria que provoca el estado de necesidad tiene la misión de remover o eliminar la situación que la provoca, el restablecer la regulación institucionalizada de los intereses y valores, logrando de esa manera superar las tensiones y fricciones dentro del sistema. Para producir el efecto deseado, el sujeto que actúa tiene que adoptar módulos de conducta capaces de incidir efectivamente en la situación irregular, propiciando en ella un cambio o modificación.

Las conductas a emprender por el sujeto, requieren conciencia de actuación, su conducta debe dirigirse a la transformación y superación de la situación irregular de forma tal que su efectividad 
permita la recuperación de un Estado conforme a las previsiones de los preceptos jurídicos destinados a regir la cotidianidad. Ahora bien, la conducta necesaria puede ser positiva o negativa; la adopción de comportamientos proactivos que modifiquen efectivamente la realidad sobre la cual se actúa o también una omisión o abstención que permita mantener una situación que permita el tránsito a otra.

La conducta podrá incidir o alterar el ámbito fáctico o jurídico de la realidad institucional. En el estado de necesidad que aspira restituir la institucionalidad se tiene el propósito de reproducir en la realidad las condiciones jurídicas para la eficiencia del Estado de Derecho, removiendo y alterando las expresiones jurídicas públicas de quienes distorsionan la realidad.

Como quiera que la reposición de la institucionalidad entraña la reinstauración de un sistema de valores, la función estimativa adquiere aquí una particular relevancia para la evaluación del cese del estado de necesidad y la habilitación de la juridicidad extraordinaria. Creemos que dada la magnitud del quebrantamiento y la entidad de la irrupción para la restitución y la necesidad de restablecer la normalidad, la habilitación para la juridicidad extraordinaria culminará tan pronto como se alcancen resultados mínimos que aseguren la progresiva conquista del éxito. De allí que cuando, en el caso de Venezuela, se han propuesto más objetivos que concretas acciones, se eligió una manera idónea de hacerlo; son objetivos a alcanzar, sin referencias temporales o a acciones concretas, se disponen de ellos según las circunstancias surgidas de la complejidad política y que podrían ser modificadas considerando su efectividad, practicidad y viabilidad.

\section{IV.CONCLUSIONES}

En Occidente la constitucionalidad del Estado es concebida como espacio en el cual el disfrute de la iusfundamentalidad, de una democracia en libertad, conduzca al despliegue vital, conforme a las aspiraciones de la población; para asegurar la efectividad y vigencia de dicho modelo cultural, se crea una forma institucional en el Estado que, desde el punto de vista funcional, se concibe como un modo de gobernabilidad para, por y desde los ciudadanos.

En Venezuela, los artículos 2, 3, 6, 7 y 19 de la CNRBV reflejan un sistema democrático y suscriben una institucionalidad política con un profundo contenido axiológico, que se traduce en un sentido fuerte del despliegue vital. Esta elección realizada por el constituyente de 1999 tiene que concebirse como los preceptos jurídicos rectores de la juridicidad ordinaria, diaria, que rige la cotidianidad.

A partir del año 2003, Venezuela inicia un proceso de desarticulación institucional ideológicamente planificado, que en la actualidad se refleja en un proceso de desaparición del Estado y la 
desaparición definitiva de la institucionalidad del país. La situación amenaza con dar al traste con la cultura y los valores de la convivencia política y social de los venezolanos, a la vez que los derechos fundamentales se encuentran en franco deterioro, o simplemente no existen.

La anormalidad de la realidad descrita exige del Derecho una reacción acorde, de allí que se recurra a la figura del estado de necesidad, figura que, aunque presente en varias instituciones del Derecho Público e históricamente activa, se ha relegado en su consideración jurídica.

Pero, en el caso de la emergencia institucional y de sobrevivencia del Estado venezolano, la Constitución Nacional proporciona en los artículos 333 y 350, los materiales para construir una teoría del estado de necesidad constitucional para el restablecimiento de la institucionalidad, que permita aportar una explicación justificativa de la asunción por la presidencia de la Asamblea Nacional, de las potestades de la presidencia de la República, de manera interina.

El examen de los distintos aspectos del problema y de algunos de sus supuestos de procedencia permite explicar, justificar y legitimar la acción política y jurídica emprendida por el Presidente de la Asamblea Nacional, ciudadano Juan Guaidó.

\section{REFERENCIAS BIBLIOGRÁFICAS}

Alto Comisionado de Naciones Unidas para los Refugiados (ACNUR) y Organización Internacional para las Migraciones (OIM). (2019). Plataforma de Coordinación para Refugiados y Migrantes de Venezuela. Nueva York: ACNUR/OIM. Recuperado de https://r4v.info/es/ situations/platform

Asamblea Nacional Constituyente. (1999). Constitución de la República Bolivariana de Venezuela. Caracas, Venezuela: Gaceta Oficial Nº 36.860 de 30 de diciembre de 1999.

Bechara, A. (2015). Aproximación teórica al concepto de estado: distinciones en torno a Heller, Jellinek y Carré de Malberg. Revista Jurídica Mario Alario D'Filippo, 7, (14): 72-84. Recuperado de DOI: https://doi.org/10.32997/2256-2796-vol.7-num.14-2015-1518

Benda, Maihofer, Vogel, Hesse y Heyde. (2001). Manual de Derecho Constitucional. Madrid, España: Marcial Pons, Ediciones Jurídicas y Sociales. Pág. 292.

Bozo de Carmona, Ana Julia (2004) Sobre la condición Postmoderna, claves para debatir en torno al modelo epistemológico, la subjetividad, la ética, la historia y la identidad. En Posmodernidades: La obra de Michel Maffesoli revisitada (Lanz, R. Coord.). Caracas, Venezuela: MonteÁvila Ed. 
Bozo de Carmona, A. (2014). La Democracia igualitarista no es mi apuesta. En Universidad Austral de Chile, Universidad de Carabobo, Universidad de Los Andes, Universidad de Oriente Editores, Miradas Múltiples, Homenaje a Rigoberto Lanz (pp. 267-274) Caracas, Venezuela: Bid\&Co Ed.

Bozo de Carmona. A. (2019). Crónica de una muerte anunciada. En Universidad Austral de Chile Editor, ¿Qué sucede en Venezuela? (pp. 186-195) Santiago de Chile: Bid\&Co Ed.

Carmona Urdaneta, Wilmer (1998) Manual de Derecho Romano. Caracas, Venezuela: Mc Graw Hill Editores

Coing, H. (1996). Derecho privado europeo. Madrid, España: Fundación Cultural del Notariado.

Costa, E. (1930). Historia del derecho romano público y privado. Madrid, España: Editorial Reus.

Ferreyra, R. (2013). Fundamentos constitucionales. Buenos Aires, Argentina: Editora Ar S.A.

Goldschmidt, J. (2001). Principios generales del proceso. México D.F., México: Editorial Jurídica Universitaria.

Hesse, K. (2001). Escritos de Derecho Constitucional. Madrid, España: Fundación Coloquio Jurídico Europeo.

Hurtado Castrillón, L. (2015) El concepto de Justicia en Rawls: un análisis desde el contexto de la globalización de la sociedad posmoderna y la interpretación constitucional en Colombia. Revista Jurídica Mario Alario D’Filippo, 7 (14): 54-71. DOI: https://doi.org/10.32997/22562796-vol.7-num.14-2015-1517

Jakobs, G. (1995). Derecho Penal. Parte general. Fundamentos y Teoría de la Imputación. Madrid, España: Ediciones Jurídicas.

Jellinek, G. (1954). Teoría general del Estado. Buenos Aires, Argentina: Editorial Albatros.

Jescheck, H. (1981). Tratado de Derecho Penal. Parte General. Barcelona, España: Edit. Bosch.

Kaufmann, A. (1977). Teoría de las normas. Fundamentos de la Dogmática Penal Moderna. Buenos Aires, Argentina: Dapalma Ed. 
León Vargas, G. (2018). Diáspora Venezolana: Cartagena, más allá de las cifras. Revista Jurídica Mario Alario D’Filippo, 10 (20): 111-119. Recuperado de DOI: https://doi.org/10.32997/22562796-vol.10-num.20-2018-2150

Maurach, R. y Zipf, H. (1994). Derecho Penal. Parte General. Buenos Aires, Argentina: Ed. Astrea.

Mommsen, T. (2015). Compendio de derecho público romano. Madrid, España: La España Moderna Ed.

Radbruch, G. (2007). Filosofia del Derecho. Madrid, España: Editorial Reus.

Roxin, C. (1997). Derecho Penal, Parte General (Tomo I). Fundamentos: La estructura de la Teoría del Delito. Madrid, España: Civitas Ed.

Schneider, H. (1991). Democracia y constitución. Madrid, España: Centro de Estudios Constitucionales.

Tito Livio. (27- 25 A.C./1997 versión). Historia de Roma desde su fundación. Madrid, España: Editorial Gredos.

Zagrebelsky, G. (2011). El derecho dúctil. Ley, derechos, justicia. Madrid, España: Editorial Trotta. 